\title{
Creation and Preliminary Characterization of Pregnane X Receptor and Constitutive Androstane Receptor Knockout Rats ${ }^{\mathbb{\$}}$
}

\author{
Kevin P. Forbes, Evguenia Kouranova, Daniel Tinker, Karen Janowski, Doug Cortner, \\ Aaron McCoy, and Xiaoxia Cui
}

Horizon Discovery Group Company, St. Louis, Missouri

Received March 3, 2017; accepted July 13, 2017

\begin{abstract}
The nuclear receptors pregnane $X$ receptor (PXR) and constitutive androstane receptor (CAR) are closely related transcription factors that regulate the expression of phase I (cytochrome P450s) and phase II metabolizing enzymes and transporter genes in response to stimulation from xenobiotics, including prescription drugs. PXR and CAR knockout and humanized mouse models have proven useful. However, the rat being bigger in size is a preferred model system for studying drug metabolism and pharmacokinetics. Here, we report the creation and preliminary characterization of PXR and CAR knockout rats and PXR/CAR double knockout rats. Whereas the expression of phase I and II enzymes and transporter genes were not upregulated by nuclear receptor-specific agonists pregnenlone$16 \alpha$-carbonitrile and 1,4-bis-[2-(3,5-dichloropyridyloxy)] benzene in
\end{abstract}

\section{Introduction}

Biologic systems are under constant bombardment of endogenous and foreign chemicals (xenobiotics) and have evolved three types of detoxification mechanisms: modification by phase I enzymes, conjugation by phase II enzymes, and transport (Xu et al., 2005). A major family of phase I enzymes are encoded by the cytochrome P450 (P450) genes that either deactivate chemicals for their eventual excretion, or convert them into biologically active forms, primarily in the liver and the intestine. These metabolites can be subjected to further breakdown by phase II enzymes, such as transferases, for elimination. In the last phase, transporter genes contribute to the uptake or efflux of these chemicals and/or the subsequent metabolites (Dogra et al., 1998; Pavek and Dvorak, 2008)

The expression of all three phases of enzymes is believed to be regulated by transcription factors, called nuclear receptors, which bind specific chemicals (ligands). Upon ligand binding, the subset of nuclear receptors that normally reside in the cytoplasm translocate into the nucleus to modulate the transcription of genes encoding enzymes that metabolize the ligands. The pregnane $\mathrm{X}$ receptor [(PXR); official gene name NR1I2 in human and Nr1i2 in rodents] and constitutive androstane

All of the authors are full-time employees of the Horizon Discovery Group Company, a contract research organization that sells the rat models described in the paper as well as provides drug testing services using these models.

https://doi.org/10.1124/dmd.117.075788

S This article has supplemental material available at dmd.aspetjournals.org. the knockout rats, confirming the disruption of respective nuclear receptor(s), our data demonstrate that PXR appears to suppress the basal expression levels of Cyp2b2, Сyp3a23/3a1, Сyp3a2, Сур3a18, and Ugt2b1 genes, while CAR maintains Cyp2b2 and Ugt2b1 and suppresses Сyp3a9 basal expression levels. In wild-type rats, agonist binding of the nuclear receptors relieves the suppression, and target genes are expressed at levels comparable to knockout rats, with or without drug treatment. Overall, our findings are in good agreement with data obtained from human primary hepatocytes, nuclear receptor knockout cell lines, and mouse knockout models. We believe these models are a useful complement to their mouse counterparts for drug development and as importantly, for functional studies on metabolic pathways involving nuclear receptors.

ABBREVIATIONS: AF2, activation function 2; CAR, constitutive androstane receptor; KO, knockout; PCN, pregnenlone-16 $\alpha$-carbonitrile; PCR, polymerase chain reaction; PXR, pregnane X receptor; P450, cytochrome P450; TCPOBOP, 1,4-bis-[2-(3,5-dichloropyridyloxy)] benzene; WT, wild type; ZFN, zinc-finger nuclease. 
via PXR and CAR (Tolson and Wang, 2010; Aleksunes and Klaassen, 2012; Amacher, 2016)

PXR and CAR can be activated by a variety of species-specific compounds (Timsit and Negishi, 2007; Wang et al., 2012). For example, pregnenlone-16 $\alpha$-carbonitrile (PCN) is a potent ligand for rodent PXR but not for human PXR, which has a higher preference for rifampicin (Guzelian et al., 2007; Scheer et al., 2008; Slatter et al., 2009). The human CAR is strongly activated by 6-(4-chlorophenyl) imidazo[2,1-b][1,3] thiazole-5-carbaldehyde $O$-(3,4-dichloro-benzyl) oxime; however, the rodent CAR receptor has a preference for 1,4-bis-[2-(3,5dichloropyridyloxy)] benzene, 1,4-bis(pyridyloxy) benzene (TCPOBOP) but not 6-(4-chlorophenyl) imidazo-[2,1-b][1,3] thiazole-5-carbaldehyde $O$-(3,4-dichloro-benzyl) oxime (Scheer et al., 2008; Slatter et al., 2009). Another compound, phenobarbital, for example, activated both human and rodent PXR and CAR receptors, as evident by comparing phenobarbital treatment of wild-type (WT), knockout (KO), and humanized mouse models (Scheer et al., 2008).

For studies on drug metabolism and pharmacokinetics, compared with mice, the larger size of the rat offers greater blood volume for sampling and higher accuracy in drug dosing. The rat also more closely resembles human physiologically and allows easier transition into other assays, such as carcinogenicity testing. However, the rat has been under used as a model system due to the historical difficulty of its genome manipulation until the recent availability of nuclease technologies (For a review, see the special collection starting with Aitman et al., 2016). Here, we generated PXR and CAR individual and double $\mathrm{KO}$ rats and characterized the models primarily by observing the effects on phase I and II drug/xenobiotic metabolizing enzymes and transporter gene expression in the liver with and without drug stimulation.

\section{Materials and Methods}

Zinc-Finger Nucleases (ZFNs). ZFNs to target rat PXR and CAR were obtained from the Sigma-Aldrich (St. Louis, MO) CompoZR product line. Each ZFN was designed to target within exon 2. ZFN mRNA was in vitro transcribed and validated as described previously (Cui et al., 2011).

Animal Husbandry and Microinjection. Rat work in this study was performed at SAGE Laboratories, now part of the Horizon Discovery Group Company, which operated under approved animal protocols overseen by SAGE's Institutional Animal Care and Use Committee.

Sprague-Dawley rats were purchased from Charles River Laboratory (Wilmington, MA), and were housed in standard cages and maintained on a 12-hour light/dark cycle with ad libitum access to food and water. Four- to five-week-old donors were injected with $20 \mathrm{U}$ of pregnant mare serum followed by $50 \mathrm{U}$ of human chorionic gonadotropin injection after 48 hours and again before mating. Fertilized eggs were harvested a day later for injection. ZFN mRNA was injected into the pronucleus of fertilized eggs. The final concentration of ZFN mRNA was $10 \mathrm{ng} / \mu \mathrm{l}$. Recipient female rats were injected with $40 \mu \mathrm{g}$ of Luteinizing Hormone Releasing Hormone (LH-Rh) 72 hours before mating. Microinjected eggs were transferred to these pseudopregnant Sprague-Dawley recipients.

Founder Identification and Breeding. Live births from microinjections were sampled by toe clipping between 7 and 21 days after birth. Genomic DNA was purified, screened by polymerase chain reaction (PCR) with oligonucleotide primers designed to flank the ZFN target site and the PCR products were sequenced to verify mutations generated by ZFNs using methods that have been previously described (Brown et al., 2013). The following oligonucleotide primers were used for PCR reactions and sequencing: PXR, $5^{\prime}$-TCTTGGAAGAGCCTATCAACG- $3^{\prime}$ and 5'-TCCCTTACATCCTTCACAGGTC-3'; and CAR, 5'-ACTCCTCCCACATTCAGGAGA-3' and 5'-GTCTCCACACACCACACAGT- $3^{\prime}$. DNA sequencing of PCR products was performed by Elim Biopharma, Inc. (Hayward, CA). Founders with desired mutations were bred back to WT animals and then intercrossed for breeding to homozygosity and establishing colonies.
Reagents. A mouse monoclonal antibody was generated against a recombinant $\mathrm{N}$-terminal rat PXR protein (see the peptide sequence in Supplemental Fig. 4) by ProMab Biotechnologies (Richmond, CA). PCN and TCPOBOP were obtained from Sigma-Aldrich. The chemical structure for PCN can be found in Kliewer et al. (1998) and for TCРОBOP can be found in Kelley et al. (1985).

Drug Response Test. Eight-week-old male WT, $\mathrm{PXR}^{-1-}, \mathrm{CAR}^{-1-}$, and $\mathrm{PXR}^{-1-} / \mathrm{CAR}^{-1-}$ rats were treated either with $2.5 \mathrm{ml} / \mathrm{kg}$ of corn oil (vehicle), PCN in corn oil ( $40 \mathrm{mg} / \mathrm{ml}$; dose equal to $100 \mathrm{mg} / \mathrm{kg}$ ), or TCPOBOP in corn oil $(5 \mathrm{mg} / \mathrm{ml}$; dose equal to $12.5 \mathrm{mg} / \mathrm{kg}$ ) via intraperitoneal injection. PCN and ТСРОВOP treatment ranges vary in the literature; the ranges are 20-100 and $1-30 \mathrm{mg} / \mathrm{kg}$, respectively. Sixteen hours after injection, rats were euthanized and liver tissues were collected for RNA purification: WT vehicle $(n=9)$ and WT PCN and TCPOBOP $(n=6) ; \mathrm{PXR}^{-1-}$ and $\mathrm{CAR}^{-1-}$ vehicle, PCN, and TCPOBOP $(n=3)$; and $\mathrm{PXR}^{-1-} / \mathrm{CAR}^{-1-}$ vehicle $(n=6)$ and $\mathrm{PCN}$ and TCPOBOP $(n=3)$.

Quantitative Reverse Transcription PCR. Liver samples were homogenized in TRIzol Reagent (Life Technologies Carlsbad, CA) with ceramic beads using a Precellys homogenizer (PeqLab, Munich, Germany). Total RNA was isolated from homogenate and $100 \mu \mathrm{g}$ of total RNA was DNAse-I treated and purified (RNA Clean Up) using an RNeasy Mini-kit (Qiagen, Germantown, MD). First strand cDNA was synthesized from $1 \mu \mathrm{g}$ of purified RNA using the $\mathrm{RT}^{2}$ First Strand Kit from the $\mathrm{RT}^{2}$ Profiler PCR Array System (Qiagen). First strand cDNA was used in a customized $\mathrm{RT}^{2}$ Profiler PCR Array (see the gene list in Supplemental Table 1). All quantitative PCR reactions were performed following the manufacturer's recommended conditions on the Bio-Rad (Hercules, CA) CFX96 Real-Time PCR Detection System. For data analysis of the RT ${ }^{2}$ Profiler PCR Array, the Ct cutoff was set at 35 (limit of detection) and the average $\Delta \mathrm{Ct}$ was calculated by normalizing to five reference genes (Rplp1, Hprt1, Rpl13a, Ldha, and $\mathrm{ActB}$ ) for each biologic replicate.

Taqman assays (Supplemental Table 2; ThermoFisher, Waltham, MA) for phase II enzymes and transporters were performed as singleplex reactions following the manufacturer's recommended conditions on the Bio-Rad CFX96 Real-Time PCR Detection System. Biologic cDNAs were pooled and assayed in triplicate. Average fold change was calculated by normalizing to three reference genes (ActB, Hprt1, and Gapdh).

For rat PXR and CAR cDNAs, synthesis was performed as described previously with replacing the kit's random primers with Oligo $(\mathrm{dT})_{20}$ Primer (ThermoFisher), followed by PCR amplification with the following specific oligonucleotides PXR $5^{\prime}$-ATGAGACCTGAGGAGAGG- ${ }^{\prime}$ and 5'-TCAGCCGTCCGTGCTGCT-3'; CAR 5'-ATGACAGCTACTCTAACA-3' and $5^{\prime}$-CCGACTTTGGAGTCTTGACTG-3'. PCR amplified cDNAs were resolved by $2 \%$ agarose E-Gels (ThermoFisher) for verification of full-length cDNA synthesis and then TA cloned into pCR4-TOPO (ThermoFisher). DNA sequencing of cloned cDNAs was performed using T7 and T3 primers by Elim Biopharma, Inc. Sequence results were aligned together using ContigExpress within Vector NTI Advance (Version 11.5.2; ThermoFisher).

Western Blot. Briefly, $100 \mathrm{mg}$ of liver tissue from WT and $\mathrm{PXR}^{-\prime-}$ male rats was Dounce homogenized in Radioimmuno precipitation assay buffer (RIPA) buffer plus protease inhibitors. After incubating on ice, the extract was centrifuged to remove debris. The resulting supernatant was resolved by gradient protein gels, transferred to nitrocellulose, and then probed with the anti-PXR antibody at 1:500 at room temperature for 1 hour. Secondary anti-mouse heavy plus light chain (Jackson Immuno Research Laboratories, West Grove, PA) was used at 1:50,000, room temperature for 1 hour. The blot was developed with Super Signal West Pico (ThermoFisher).

\section{Results}

\section{Generation of PXR and CAR KO Rats}

The rat PXR and CAR genes both contain nine coding exons. Active ZFNs were validated to target exon 2, the first coding exon of both genes coincidently (Fig. 1). mRNAs of each pair of ZFNs were combined at 1: 1 ratio and microinjected into the pronucleus of fertilized eggs of Sprague-Dawley rats, which were then implanted into pseudo-pregnant females. One of 10 live births from PXR ZFN injections carried a 20 base pair deletion and was bred to establish a homozygous colony. Four of 12 CAR rats had modified alleles, three of which were 
A

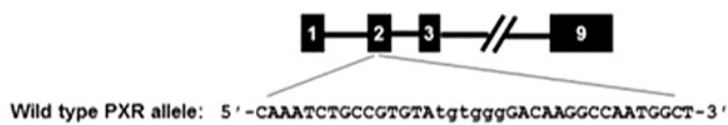

Knockout allele:

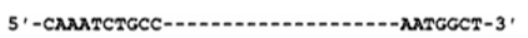

B

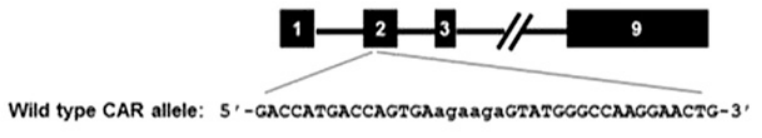

Knockout allele:
C

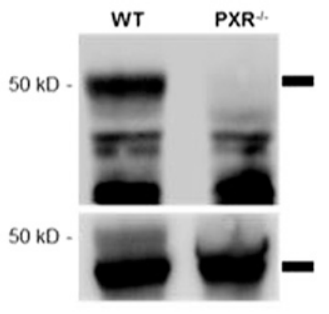

Fig. 1. Deletion map for $P X R$ and $C A R$ genes generated via ZFNs. The rat PXR (A) and CAR (B) transcripts each contain nine exons. Black boxes with numbers represent exons and dashes represent introns. A double hash mark represents exons not shown (exons 4-8 for both genes). Top sequence is the ZFN target sequence and the bottom sequence with dashes represents mutant allele. (C) WT and $\mathrm{PXR}^{-1-}$ liver protein extracts were analyzed for PXR expression by immunoblotting. Actin was used as an internal control. The size of the $50 \mathrm{kD}$ protein marker is listed on the left and the corresponding PXR and actin band on the right of the gel with a solid dash mark. determined by sequencing to have either a 10 or 12 base pair deletion. A male founder with a 10 base pair deletion was used to establish a homozygous colony. A simple PCR at the target site was used as a convenient genotyping screen to differentiate between WT, heterozygote, and homozygote alleles (Supplemental Fig. 1). Both deletions in PXR and CAR (Supplemental Fig. 2A) led to a frameshift in the coding sequence that resulted in premature termination of protein translation in the DNA binding domain (Supplemental Fig. 2B). Animals homozygous for the respective deletions are referred to as $\mathrm{PXR}^{-1-}$ and $\mathrm{CAR}^{-1-}$ rats, and their crossbreeds are referred to as $\mathrm{PXR}^{-1-} / \mathrm{CAR}^{-1-}$ rats.

\section{Confirmation of PXR and CAR Gene Disruption}

To find out whether the frameshift deletions in $\mathrm{PXR}^{-/-}$and $\mathrm{CAR}^{-1-}$ rats led to mRNA degradation via the nonsense-mediated decay pathway, we performed quantitative reverse transcription PCR on RNA extracted from liver tissue. Comparable levels of PXR and CAR mRNAs were detected in their respective KO models compared with WT rats (data not shown). The deletions did not result in PXR or CAR mRNA degradation via the nonsense-mediated decay pathway. However, we were able to demonstrate that both mRNAs contain deletions that lead to out-of-frame translation of the messages and nonfunctional proteins (Supplemental Fig. 3; sequence verification of cloned cDNAs amplified with PXR- or CAR-specific oligonucleotides from WT, $\mathrm{PXR}^{-1-}$, and $\mathrm{CAR}^{-1-}$ liver RNA).

We then performed western blots using a monoclonal antibody raised specifically against the N-terminus of the rat PXR protein (Supplemental Fig. 4, A and B) on liver protein extracts. Here, we demonstrated that the major PXR peptide was detected in WT rats but absent in $\mathrm{PXR}^{-/-}$samples (Fig. 1C), indicating PXR gene disruption by the
ZFN-introduced frameshift. We were unable to find a suitable specific antibody to detect the rat CAR protein in liver extracts.

Impact on Body Weight by Disruption of the Nuclear Receptors. Male and female WT, $\mathrm{PXR}^{-1-}, \mathrm{CAR}^{-1-}$, and $\mathrm{PXR}^{-/-} / \mathrm{CAR}^{-1-}$ rats were weighed weekly between the ages of 3-15 weeks. Over the 12-week period, male $\mathrm{CAR}^{-1-}$ and $\mathrm{PXR}^{-1-} / \mathrm{CAR}^{-1-}$ rats were both significantly lighter than WT rats $(t$ test; $P<0.02)$. However, male $\mathrm{PXR}^{-1-}$ rats were heavier than the WT rats, although not statistically significant (Fig. 2A). Female $\mathrm{PXR}^{-1-}$ rats were heavier and $\mathrm{CAR}^{-1-}$ rats were lighter than WT rats ( $t$ test; $P<0.02$; Fig. $2 \mathrm{~B}$ ) and $\mathrm{PXR}^{-/-} / \mathrm{CAR}^{-1-}$ rats were indistinguishable from WT rats (Fig. 2B). However, we have to point out that these WT and KO rats were not measured within the same time period or same season of the year, which may cause some variability. We superimposed our weight curves onto the WT rat weight curves available from the vendor webpage, and all of the weights fell within the range of 2 S.D. from the mean (Supplemental Fig. 5). We need to be cautious with our conclusions on relative weight change; however, we believe the general trend is reliable.

Regulation of Hepatic P450 Genes (Phase I Enzymes) in WT, PXR $^{-1-}$, and $\mathrm{CAR}^{-1-}$ Male Rats

We treated male WT, $\mathrm{PXR}^{-\prime-}, \mathrm{CAR}^{-\prime-}$, and $\mathrm{PXR}^{-1-} / \mathrm{CAR}^{-1-}$ rats with corn oil (vehicle), PCN (PXR agonist), or TCPOBOP (CAR agonist) in corn oil, and then collected livers and analyzed gene expression on a custom quantitative reverse transcription PCR array. The array included P450 genes, drug transporters, nuclear receptors, and controls (Supplemental Table 1). For easier comparison, the relative expression level of each gene was normalized to that of vehicle-treated WT rats such that both basal expression level changes and drug
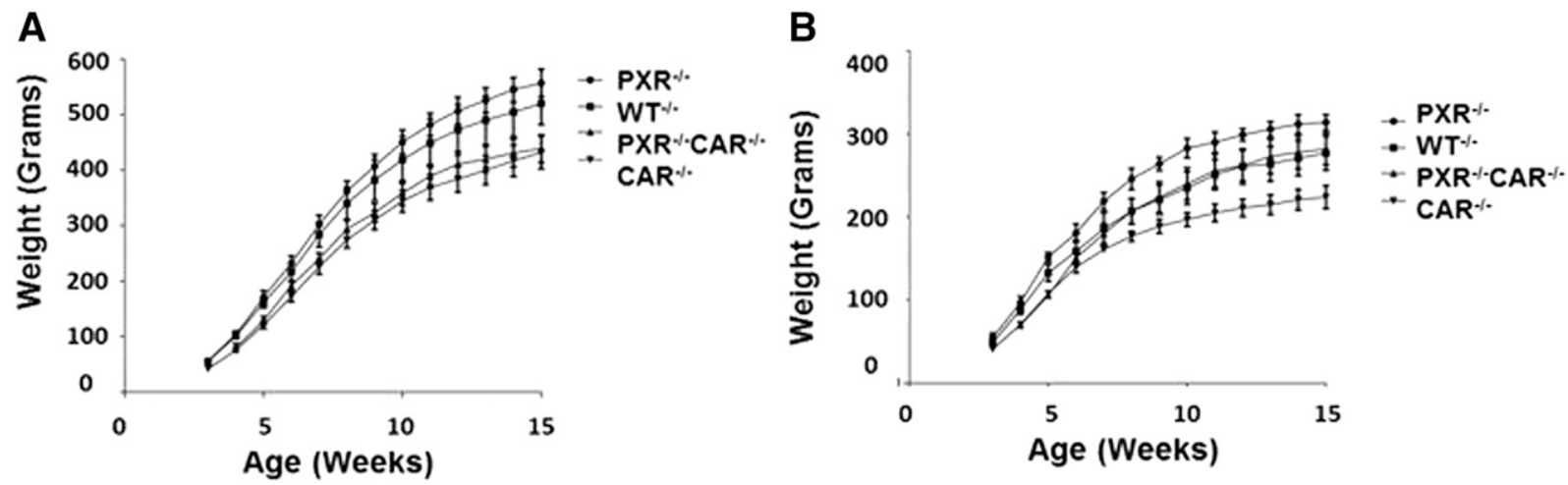

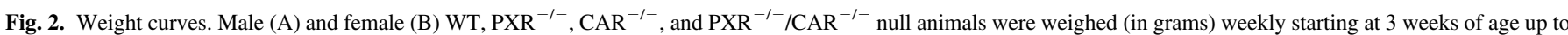

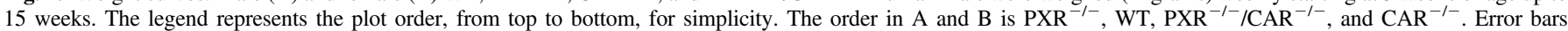
represent calculated S.D. 


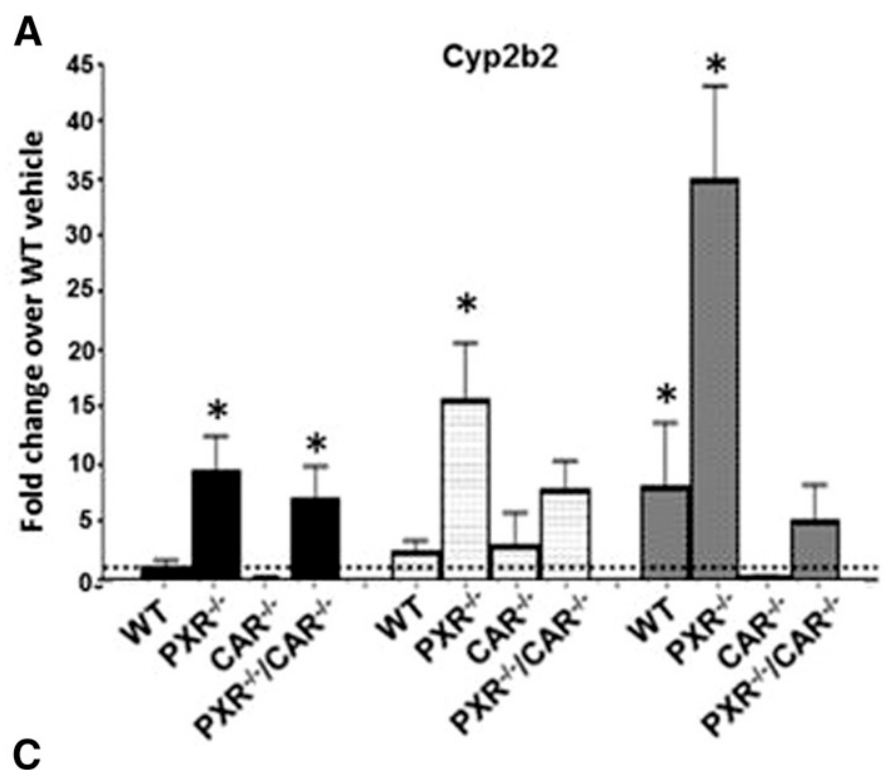

B
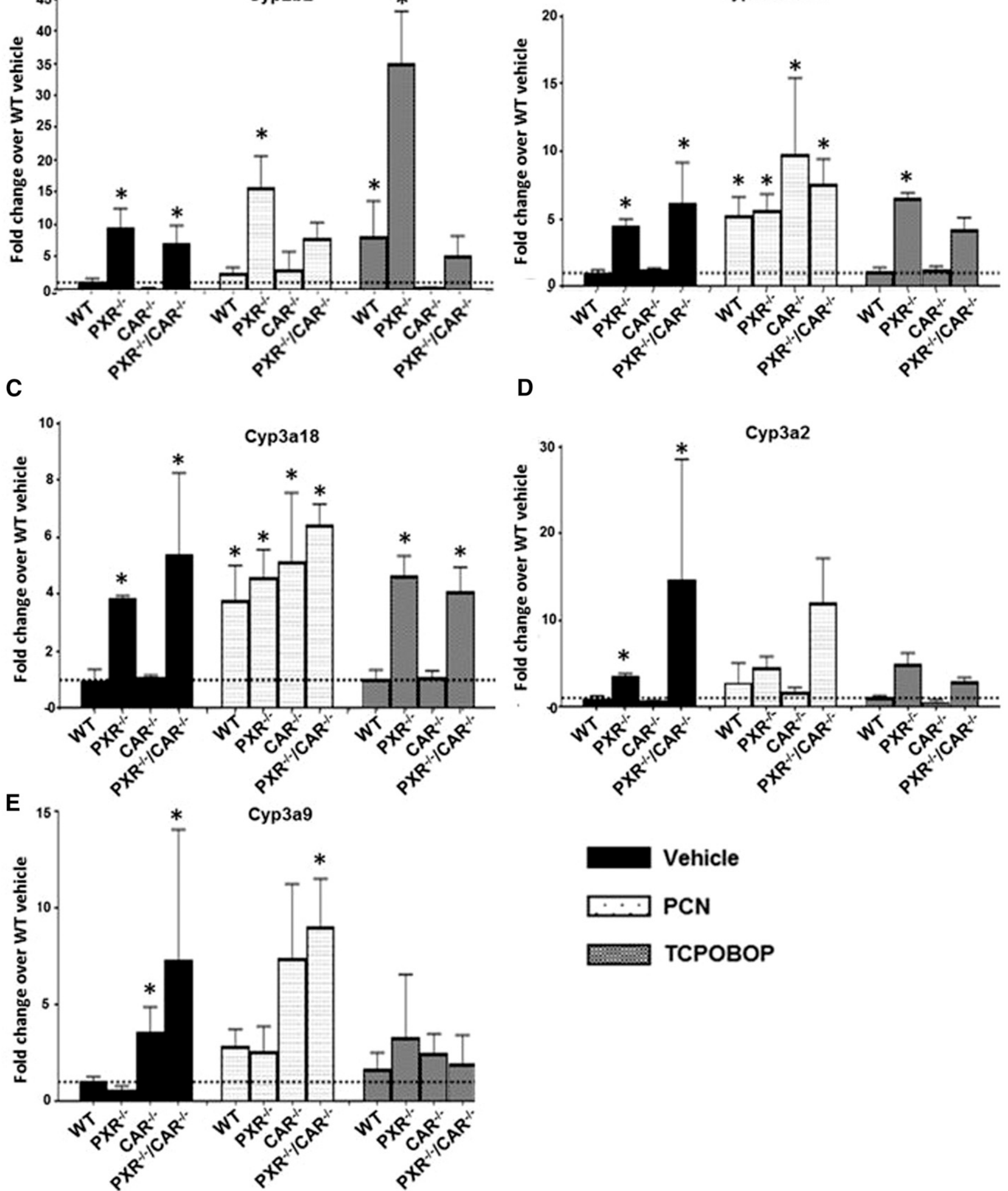

D

Fig. 3. Fold change in P450 gene expression levels in untreated and treated WT and KO rats. Vehicle (left cluster), PCN (middle cluster), and TCPOBOP (right cluster) treated rats. Cyp2b2 (A), 3a23/3a1 (B), 3a18 (C), 3a2 (D), and 3a9 (E) expression levels were normalized to WT vehicle-treated rats to calculate fold changes. Fold change calculated by dividing each $2^{-\Delta \mathrm{CT}}$ replicate (biologic) by the average WT vehicle $2^{-\Delta \mathrm{CT}}$. Error bars are the calculated S.D. between the biologic replicates. Dashed lines represent normalized WT vehicle average value of 1 . Asterisk marks $(*)$ represent calculated $P$ values; two-way analysis of variance followed by Tukey's multiple comparisons test $\left(P<0.05\right.$, Tukey's). Bars marked with an asterisk mark $\left(^{*}\right)$ are significantly different from WT vehicle-treated rats. 
treatment-mediated expression regulation could be captured in the same graph.

The prototypical P450 genes regulated by PXR and CAR, the Cyp2b and the Cyp3a subfamily members, were analyzed and the results are given in Fig. 3 and Supplemental Table 3. Vehicle-treated samples are shown in the left clusters of each panel in Fig. 3. Cyp2b2 expression was more than 7-fold higher than that of WT in both $\mathrm{PXR}^{-1-}$ and $\mathrm{PXR}^{-1-}$, $\mathrm{CAR}^{-I-}$ rats, whereas in $\mathrm{CAR}^{-1-}$ rats, Cyp2b2 mRNA was reduced to about one-tenth of the WT level (Fig. 3A). Cyp3a1/3a23, Cyp3a18, and Cyp3a2 expression was also elevated significantly in $\mathrm{PXR}^{-/-}$and $\mathrm{PXR}^{-1-} / \mathrm{CAR}^{-1-}$ rats when compared with WT rats (Fig. 3, B-D). However, these genes were not affected by CAR disruption alone (see $\mathrm{CAR}^{-1-}$ in Fig. 3, B-D). On the other hand, expression levels of another Cyp3a family member, Cyp3a9, was increased compared with WT levels in $\mathrm{CAR}^{-1-}$ and $\mathrm{PXR}^{-1-} / \mathrm{CAR}^{-1-}$ rats but was not affected in $\mathrm{PXR}^{-1-}$ rats (Fig. 3E). Supplemental Table 3 gives a detailed statistical analysis of the basal expression levels for these five genes. However, no significant change in the basal expression level of the other genes within the array, including Cyp1a2, Abcb1a (Mdr1a), Abcb4 (Mdr2), Abcc1 (Mrp1), Abcc2 (Mrp2), and Abcc3 (Mrp3), was observed (see the left cluster in Supplemental Fig. 6).

The chemical activation of the rat Cyp2b2 and Cyp3a subfamily members Cyp3a23/3a1, Cyp3a18, and Cyp3a2 upon the administration of PCN over vehicle treatment was observed in $\mathrm{WT}$ and $\mathrm{CAR}^{-\prime-}$ rats, as expected for a PXR agonist (see the middle clusters in Fig. 3; Table 1). The increased induction of Cyp2b2 by PCN observed in the $\mathrm{CAR}^{-1-}$ rats compared with WT rats reflects the activation by PXR upon PCN treatment, which compensates for the reduced CAR-dependent basal expression (Fig. 3A). Interestingly, Cyp3a9 expression was activated by $\mathrm{PCN}$ in WT and $\mathrm{PXR}^{-1-}$ rats and with no significant change in $\mathrm{CAR}^{-1-}$ rats (see the middle clusters in Fig. 3E; Table 1). However, the expression levels of Cyp1a2, Abcb1a, Abcb4, Abcc1, Abcc2, and

TABLE 1

Fold change of gene expression in PCN: vehicle-treated rats

Values are fold change PCN to vehicle treated, \pm S.D. Fold change between genotypes analyzed by one-way analysis of variance followed by Tukey's multiple comparisons test.

\begin{tabular}{|c|c|c|c|c|}
\hline P450 Gene & WT & $\mathrm{PXR}^{-1-}$ & $\mathrm{CAR}^{-1-}$ & $\mathrm{PXR}^{-1-} / \mathrm{CAR}^{-1-}$ \\
\hline Сур $2 b 2$ & $\begin{array}{c}2.42 * \\
( \pm 0.85)\end{array}$ & $\begin{array}{c}1.65 \\
( \pm 0.50)\end{array}$ & $\begin{array}{c}26.76 \\
( \pm 23.56)\end{array}$ & $\begin{array}{c}1.09 \\
( \pm 0.35)\end{array}$ \\
\hline Сур3а23/3a1 & $\begin{array}{c}5.30 * \\
( \pm 1.32)\end{array}$ & $\begin{array}{c}1.23 * * \\
( \pm 0.27)\end{array}$ & $\begin{array}{c}8.08 \\
( \pm 4.60)\end{array}$ & $\begin{array}{c}1.24 * * \\
( \pm 0.29)\end{array}$ \\
\hline Сур $3 a 18$ & $\begin{array}{c}3.78 * \\
( \pm 1.23)\end{array}$ & $\begin{array}{c}1.19 * * \\
( \pm 0.24)\end{array}$ & $\begin{array}{c}4.86^{*} \\
( \pm 2.22)\end{array}$ & $\begin{array}{c}1.19 * * \\
( \pm 0.13)\end{array}$ \\
\hline Сур $3 a 2$ & $\begin{array}{c}2.83 * \\
( \pm 2.23)\end{array}$ & $\begin{array}{c}1.25 \\
( \pm 0.36)\end{array}$ & $\begin{array}{c}2.58^{*} \\
( \pm 0.70)\end{array}$ & $\begin{array}{c}0.82 \\
( \pm 0.35)\end{array}$ \\
\hline Сур $3 a 9$ & $\begin{array}{c}2.89 * \\
( \pm 0.84)\end{array}$ & $\begin{array}{c}4.31^{*} \\
( \pm 2.03)\end{array}$ & $\begin{array}{c}2.07 \\
( \pm 1.06)\end{array}$ & $\begin{array}{c}1.24 \\
( \pm 0.33)\end{array}$ \\
\hline Slco1a2 & $\begin{array}{c}3.30 * \\
( \pm 1.13)\end{array}$ & $\begin{array}{c}1.00 * * \\
( \pm 0.20)\end{array}$ & $\begin{array}{c}3.82 * \\
( \pm 1.01)\end{array}$ & $\begin{array}{c}0.93 * * \\
( \pm 0.15)\end{array}$ \\
\hline Slcola1 & $\begin{array}{c}1.34 \\
( \pm 0.55)\end{array}$ & $\begin{array}{c}0.81 \\
( \pm 0.37)\end{array}$ & $\begin{array}{c}0.65 \\
( \pm 0.08)\end{array}$ & $\begin{array}{c}0.64 \\
( \pm 0.13)\end{array}$ \\
\hline Slc10a1 & $\begin{array}{c}1.06 \\
( \pm 0.36)\end{array}$ & $\begin{array}{c}1.06 \\
( \pm 0.21)\end{array}$ & $\begin{array}{c}0.94 \\
( \pm 0.25)\end{array}$ & $\begin{array}{c}0.85 \\
( \pm 0.14)\end{array}$ \\
\hline Ugt2b1 & $\begin{array}{c}1.87 \\
( \pm 0.62)\end{array}$ & $\begin{array}{c}0.68 \\
( \pm 0.18)\end{array}$ & $\begin{array}{l}3.65 * * * * \\
( \pm 0.97)\end{array}$ & $\begin{array}{c}0.62 \\
( \pm 0.17)\end{array}$ \\
\hline Ugtla6 & $\begin{array}{c}0.70 \\
( \pm 0.24)\end{array}$ & $\begin{array}{c}0.68 \\
( \pm 0.13)\end{array}$ & $\begin{array}{c}0.79 \\
( \pm 0.21)\end{array}$ & $\begin{array}{c}0.43 \\
( \pm 0.07)\end{array}$ \\
\hline Sult2a2 & $\begin{array}{c}5.71 * \\
( \pm 1.91)\end{array}$ & $\begin{array}{c}0.67 * * \\
( \pm 0.18)\end{array}$ & $\begin{array}{c}5.04 * \\
( \pm 1.35)\end{array}$ & $\begin{array}{c}0.43 * * \\
( \pm 0.12)\end{array}$ \\
\hline Ephx1 & $\begin{array}{c}1.24 \\
( \pm 0.42)\end{array}$ & $\begin{array}{c}0.80 \\
( \pm 0.16)\end{array}$ & $\begin{array}{c}0.84 \\
( \pm 0.22)\end{array}$ & $\begin{array}{c}0.43 \\
( \pm 0.07)\end{array}$ \\
\hline Gstm4 & $\begin{array}{c}0.82 \\
( \pm 0.28)\end{array}$ & $\begin{array}{c}0.70 \\
( \pm 0.14)\end{array}$ & $\begin{array}{c}0.64 \\
( \pm 0.17)\end{array}$ & $\begin{array}{c}0.93 \\
( \pm 0.15)\end{array}$ \\
\hline
\end{tabular}

$* P<0.05$, significantly different from vehicle treated, same genotype $(t$ test $) ; * P<0.05$, significantly different from WT (Tukey's).
Abcc3 (the other genes within the array; data not shown) were unchanged upon PCN treatment in all models (see the middle cluster in Supplemental Fig. 6).

Treatment with the known CAR agonist TCPOBOP activated Cyp2b2 in WT and $\mathrm{PXR}^{-1-}$ rats only, confirming its specificity for a functional CAR gene. Cyp3a23/3a1, Cyp3a18, Cyp3a2, and Cyp3a9 (see the right clusters in Fig. 3; Table 2), along with Cyp1a2, Abcb1a, Abcb4, Abcc1, Abcc2, and Abcc3 (the other genes within the array; data not shown), were not affected by TCPOBOP treatment in any of the models (see the right cluster in Supplemental Fig. 6).

\section{Regulation of Hepatic Transporters and Phase II Enzymes in WT, PXR $^{-1-}$, and CAR ${ }^{-1-}$ Male Rats}

Solute carrier transporters Slco1a1 (Oatp1), Slco1a2 (Oatp2), Slc47a1 (Mate1), and Slc10a1 (Ntcp) were not assayed on the array. We screened RNAs from WT, $\mathrm{PXR}^{-1-}, \mathrm{CAR}^{-1-}$, and $\mathrm{PXR}^{-1-} / \mathrm{CAR}^{-1-}$ rats for changes in basal and activated (PCN and TCPOBOP treatment) expression levels for these transporters separately (Fig. 4; see the Taqman assays in Supplemental Table 2; see the statistical analysis in Supplemental Table 3 and Tables 1 and 2). Oatp2 was activated 3- to 4-fold by PCN treatment in WT and $\mathrm{CAR}^{-1-}$ rats and unchanged in $\mathrm{PXR}^{-/-}$and $\mathrm{PXR}^{-/-} / \mathrm{CAR}^{-/-}$rats (see the middle cluster in Fig. 4A). There were no observed changes to Oatp1 and Ntcp transporter mRNA levels (Fig. 4, B and C) and Mate1 was undetected in our assay (data not shown). In addition, no significant changes were observed in basal expression level or by TCPOBOP treatment in WT or any of the KO models (see the left and right clusters in Fig. 4; Table 2).

Phase II enzymes UDP-glucuronosyltransferase (Ugt1a6, Ugt2b1, and Ugt2b7), sulfotransferase (Sult2a2), glutathione transferase (Gstm4), and Ephx1 basal and activated mRNA levels were determined using the same methods. Basal expression levels of Ugt2b1 were trending down 2 -fold in $\mathrm{CAR}^{-/-}$rats and upregulated $\sim 4$-fold in

TABLE 2

Fold change of gene expression in TCPOBOP: vehicle-treated rats

Values are fold change TCРОВOP to vehicle treated, \pm S.D. Fold change between genotypes analyzed by one-way analysis of variance followed by Tukey's multiple comparisons test.

\begin{tabular}{lcccc}
\hline P450 Gene & WT & $\mathrm{PXR}^{-1-}$ & $\mathrm{CAR}^{-1-}$ & $\mathrm{PXR}^{-1-} / \mathrm{CAR}^{-1-}$ \\
\hline Cyp2b2 & $6.18^{*}$ & $3.65^{*}$ & $1.42^{* *}$ & $0.71 * *$ \\
& $( \pm 2.38)$ & $( \pm 0.83)$ & $( \pm 1.05)$ & $( \pm 0.41)$ \\
Cyp3a23/3a1 & 1.08 & 1.44 & 0.99 & 0.69 \\
& $( \pm 0.31)$ & $( \pm 0.08)$ & $( \pm 0.22)$ & $( \pm 0.14)$ \\
Cyp3a18 & 1.06 & 1.21 & 1.00 & 0.76 \\
& $( \pm 0.29)$ & $( \pm 0.17)$ & $( \pm 0.23)$ & $( \pm 0.15)$ \\
Cyp3a2 & 1.07 & 1.38 & 0.87 & 0.20 \\
& $( \pm 0.23)$ & $( \pm 0.34)$ & $( \pm 0.24)$ & $( \pm 0.03)$ \\
Cyp3a9 & 1.68 & 5.38 & 0.70 & 0.27 \\
& $( \pm 0.84)$ & $( \pm 5.35)$ & $( \pm 0.27)$ & $( \pm 0.20)$ \\
Slco1a2 & 1.10 & 0.88 & 0.95 & 1.26 \\
Slco1a1 & $( \pm 0.17)$ & $( \pm 0.24)$ & $( \pm 0.31)$ & $( \pm 0.28)$ \\
& 0.82 & 0.79 & 0.63 & 1.19 \\
Slc10a1 & $( \pm 0.14)$ & $( \pm 0.37)$ & $( \pm 0.11)$ & $( \pm 0.24)$ \\
& 0.92 & 1.25 & 1.15 & 1.26 \\
Ugt2b1 & $( \pm 0.14)$ & $( \pm 0.35)$ & $( \pm 0.37)$ & $( \pm 0.28)$ \\
& 1.04 & 0.94 & 0.55 & 1.45 \\
Ugt1a6 & $( \pm 0.014)$ & $( \pm 0.09)$ & $( \pm 0.19)$ & $( \pm 0.84)$ \\
Sult2a2 & 0.78 & 1.15 & 1.26 & 1.21 \\
Ephx1 & $( \pm 0.12)$ & $( \pm 0.32)$ & $( \pm 0.41)$ & $( \pm 0.27)$ \\
Gstm4 & 1.20 & $0.42 *$ & $2.35 *$ & 1.16 \\
& $( \pm 0.16)$ & $( \pm 0.04)$ & $( \pm 0.80)$ & $( \pm 0.67)$ \\
& 1.34 & 1.74 & 0.85 & 1.54 \\
& $( \pm 0.20)$ & $( \pm 0.48)$ & $( \pm 0.28)$ & $( \pm 0.34)$ \\
& 0.65 & 0.92 & 0.59 & 1.26 \\
& $( \pm 0.10)$ & $( \pm 0.25)$ & $( \pm 0.19)$ & $( \pm 0.28)$ \\
\hline
\end{tabular}

$* P<0.05$, significantly different from vehicle treated, same genotype $(t$ test). 
A

SIco1a2

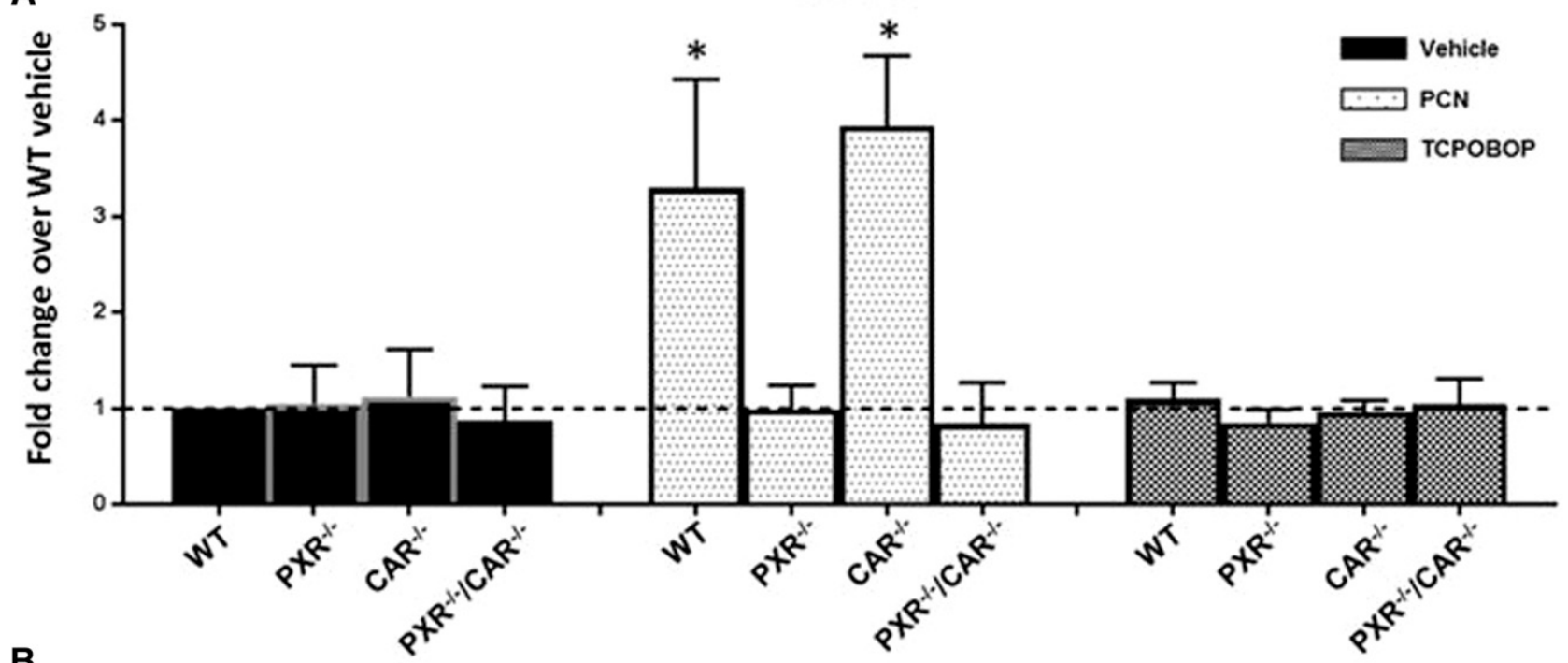

B
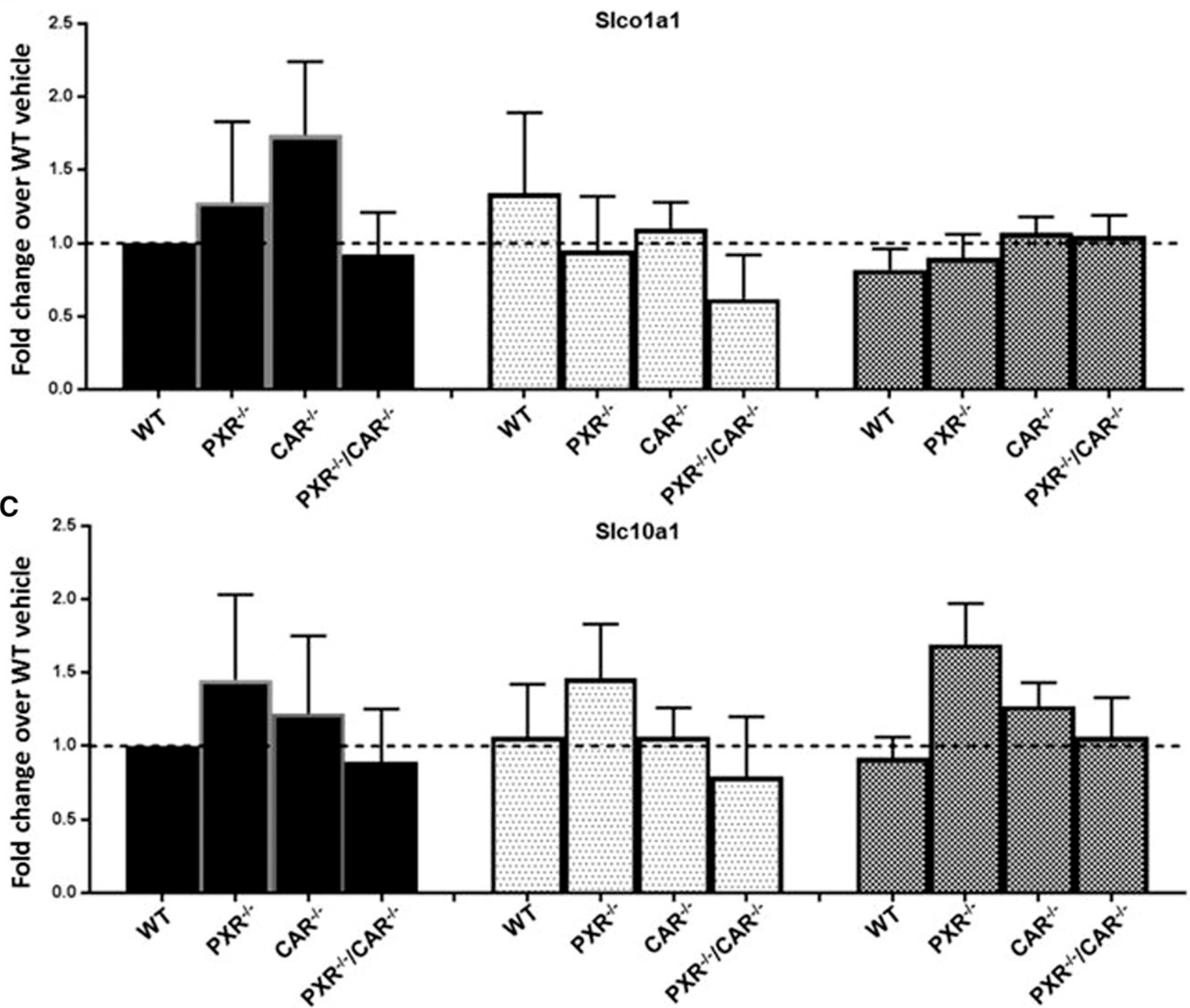

Fig. 4. Fold change in transporter gene expression levels in untreated and treated WT and KO rats. Vehicle (left cluster), PCN (middle cluster), and TCPOBOP (right cluster) treated rats. Slcola2 (A), Slcola1 (B), and Slc10a1 (C) expression levels were normalized to WT vehicle-treated rats to calculate fold changes. Fold change calculated by dividing each $2^{-\Delta \mathrm{CT}}$ replicate reaction by the average WT vehicle $2^{-\Delta \mathrm{CT}}$. Error bars are calculated S.D. between replicate reactions. Dashed lines represent normalized WT vehicle average value of 1 . Asterisk marks $(*)$ represent calculated $P$ values; two-way analysis of variance followed by Tukey's multiple comparisons test $(P<0.05$, Tukey's). Bars marked with an asterisk mark $(*)$ are significantly different from WT vehicle-treated rats. 
A

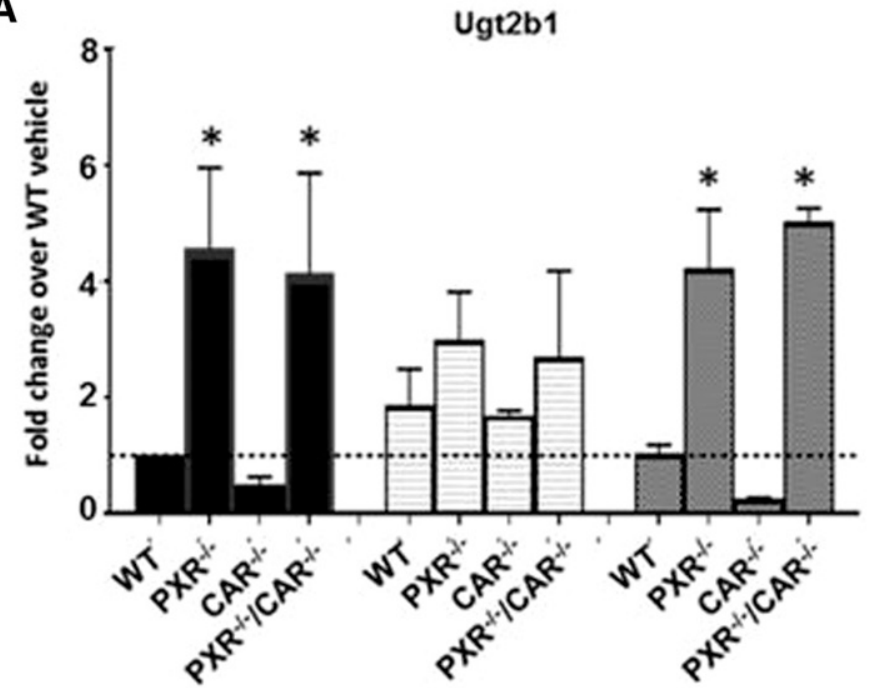

C

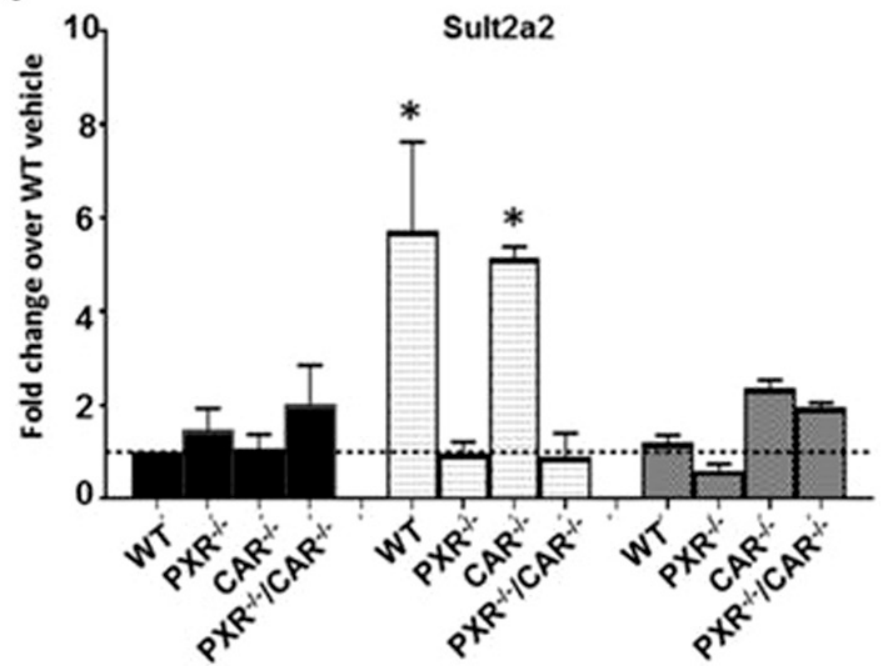

E

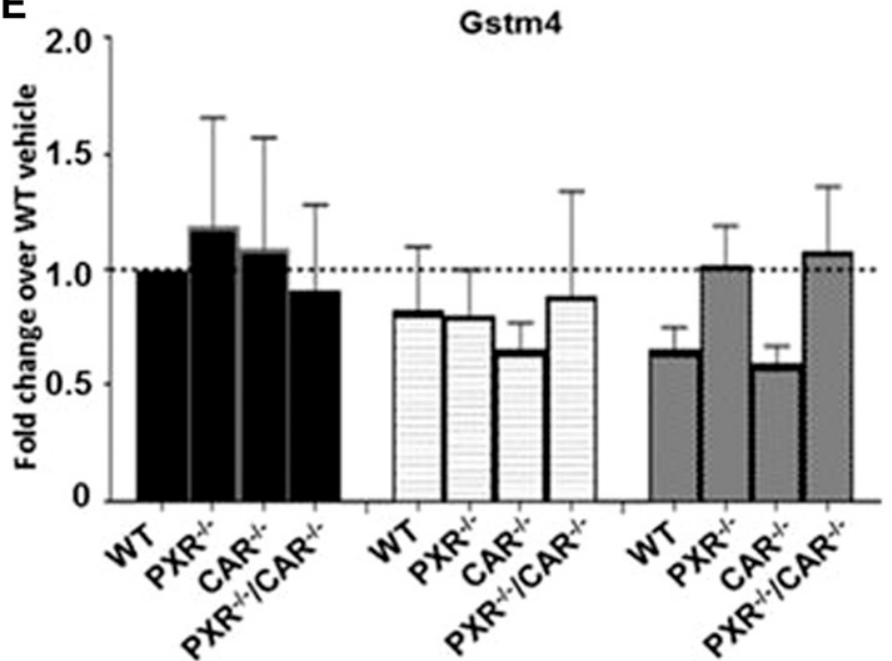

B

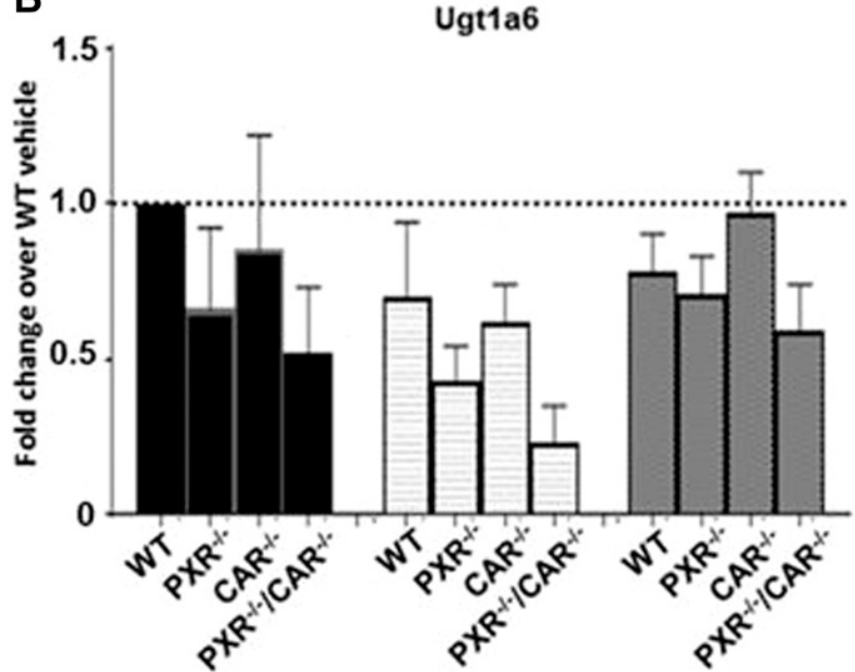

D

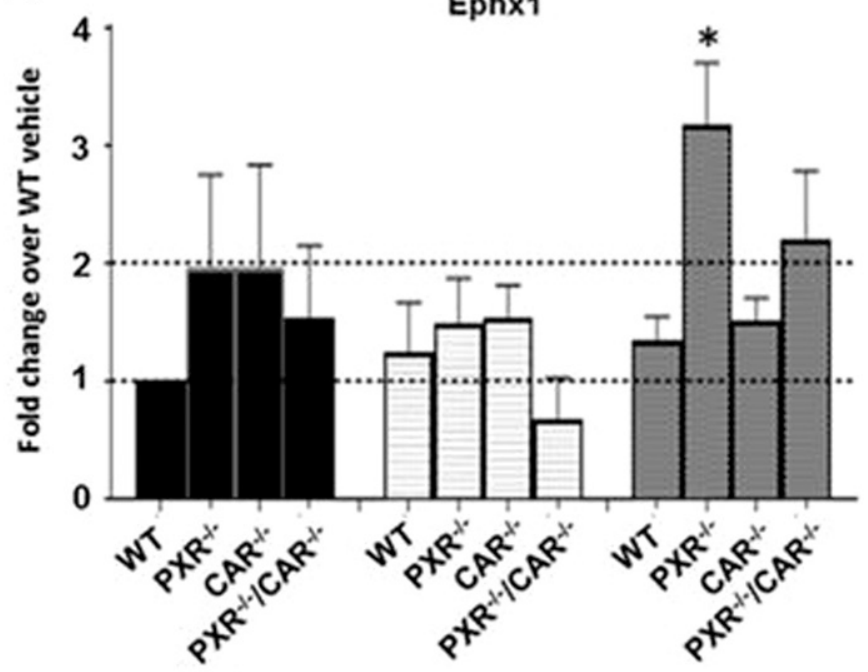

Vehicle

$\because \mathrm{PCN}$

TCPOBOP

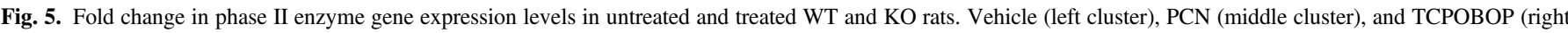

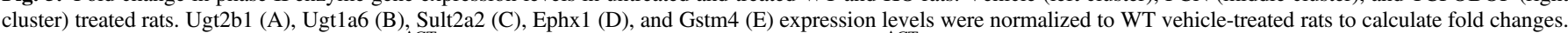

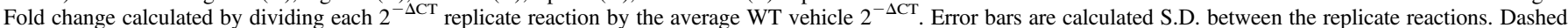

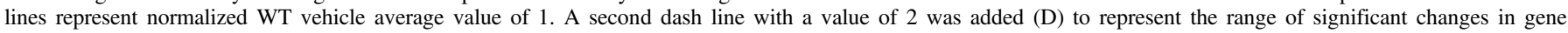

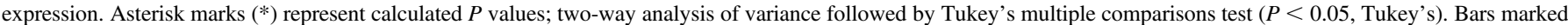
with an asterisk mark $\left(^{*}\right)$ are significantly different from WT vehicle-treated rats. 
$\mathrm{PXR}^{-1-}$ and $\mathrm{PXR}^{-1-} / \mathrm{CAR}^{-1-}$ rats, with no observed changes in Ugt1 a6 when compared with WT (see the left clusters in Fig. 5, A and B; Supplemental Table 3). No significant changes were observed during PCN or TCPOBOP activation (see the middle and right clusters in Fig. 5, $A$ and B) and Ugt2b7 was undetected in our assay (data not shown). Sult2a2 was activated $\sim 5$ - to 6 -fold by PCN treatment in WT and $\mathrm{CAR}^{-1-}$ rats and was unchanged in $\mathrm{PXR}^{-1-}$ and $\mathrm{PXR}^{-1-} / \mathrm{CAR}^{-1-}$ rats (see the middle cluster in Fig. 5C; Table 1). Ephx1was slightly induced by TCPOBOP in $\mathrm{PXR}^{-/-}$and $\mathrm{PXR}^{-/-} / \mathrm{CAR}^{-/-}$rats (see the right cluster in Fig. 5D) and we observed no changes in Gstm4 mRNA levels (Fig. 5E).

\section{Discussion}

In this study, we generated and characterized new KO rat models for the nuclear receptors PXR and CAR. We observed changes in body weight, basal gene expression levels, and loss of receptor-mediated activation via exogenous ligands within these $\mathrm{KO}$ lines.

Body weight change in the $\mathrm{KO}$ models confirms the involvement of the nuclear receptors in metabolic pathways other than xenobiotic detoxification. In both genders, disruption of PXR led to weight gain, although in male rats the increase was not statistically significant. In addition, the male double KO rats were significantly lighter than WT, whereas female double $\mathrm{KO}$ rats were comparable to WT counterparts. The overall trend in rats is that disruption of PXR and CAR had an opposite effect on weight. This suggests that these nuclear receptors function on regulating basal expression levels of opposing sets of genes contributing to body mass. Their effect canceled each other out in the female rats. Similar observations on gender differences have been made in mice (Uppal et al., 2005; Anakk et al., 2007), raising the question of whether it is sufficient to only use males for pharmacological tests as the standard method currently used. Regardless, weight change is the first indication that the function of these genes was in fact altered in the $\mathrm{KO}$ animals.

As expected, we observed upregulation of Cyp2b2, Cyp3a23/3a1, 3a18, 3a2, 3a9, Slco1a2 (Oatp2), and Sult2a2 genes by PCN compared with vehicle in WT rats, but not in $\mathrm{PXR}^{-/-}$(Cyp3a9 was the exception; see the subsequent discussion on CAR-dependent $\mathrm{PCN}$ activation) and $\mathrm{PXR}^{-1-} / \mathrm{CAR}^{-1-}$ rats, and upregulation of Cyp2b2 by TCPOBOP in WT and $\mathrm{PXR}^{-1-}$ rats, but not in $\mathrm{CAR}^{-1-}$ and $\mathrm{PXR}^{-1-} / \mathrm{CAR}^{-1-}$ rats. It is well documented that PCN and TCPOBOP activation of these $\mathrm{P} 450$ genes is PXR and CAR dependent in rodents, respectively. The induction of the Oatp2 transporter by $\mathrm{PCN}$ has previously been reported in mice (Staudinger et al., 2003; Slatter et al., 2009) and rats (Guo et al., 2002; Slatter et al., 2009) and sulfotransferase gene activation in primary rat and human hepatocytes (Fang et al., 2005) and mice (Aleksunes and Klaassen, 2012; Cui and Klaassen, 2016) is PXR dependent. This confirms that hepatic regulation of these genes in rats by PCN is PXR dependent. We also observed a slight induction of Ephx1 under TCPOBOP activation in $\mathrm{PXR}^{-\prime-}$ (see the right cluster in Fig. 5D) when compared with WT vehicle-treated rats. However, this was not significant when compared to vehicle-treated $\mathrm{PXR}^{-1-}$ rats, more than likely due to the slight increase in endogenous Ephx1 levels in these models.

Basal gene expression levels of Cyp2b2, Cyp3a23/3a1, 3a18, 3a2, and Ugt2b1 were increased in $\mathrm{PXR}^{-1-}$ rats. Xie et al. (2000) first reported on a PXR-null mouse and observed no changes in Cyp3a11 expression levels. However, subsequent studies around PXR in both mice and humans reported changes in genes closely related to the rat counterparts assessed in the current study. In PXR-null mice, Cyp3a11, Oatp2, and Mrp3 had higher basal mRNA levels in the liver than in WT mice (Staudinger et al., 2001, 2003). In humans, allelic variants of PXR genes found in Caucasians and African Americans exhibit altered basal and/or induced transactivation of the CYP3A4 gene (Hustert et al., 2001; Zhang et al., 2001). Compared with $\mathrm{PXR}^{-1-}$, in $\mathrm{CAR}^{-1-}$ rats endogenous levels of Cyp3a9 were increased and Cyp2b2 and Ugt2b1 levels were decreased. In HepaRG cells, an in vitro proliferationcompetent human hepatocyte line that closely resembles primary hepatocytes, the disruption of CAR led to changes in basal transcription levels of several drug metabolizing and transporter genes ( $\mathrm{Li}$ et al., 2016). In CAR KO mice, Cyp2b13 (the mouse equivalent of rat Cyp2b21) expression was upregulated, whereas Cyp2b10 (the mouse equivalent of rat Cyp2b2) expression was downregulated (Hernandez et al., 2010). In addition to changes in P450 levels, some phase II enzymes and transporter mRNA expression levels were altered gender dependently in the liver and small intestine of PXR and CAR KO mice (Cheng and Klaassen, 2006; Aleksunes and Klaassen, 2012). These reported changes in endogenous gene expression levels are comparable to our observations in $\mathrm{PXR}^{-/-}$and $\mathrm{CAR}^{-1-}$ rats. Changes caused by PXR or CAR disruption in basal gene expression levels can confound data analysis when only the ratio of vehicle versus treated samples is looked at.

The disruption of PXR greatly increased the expression levels of Cyp2b2 and Ugt2b1, suggesting that PXR suppresses them directly or indirectly in the absence of exogenous ligand, whereas CAR counterbalances PXR in maintaining their endogenous expression, demonstrated by the diminished Cyp2b2 and Ugt2b1 expression in $\mathrm{CAR}^{-1-}$ rats (Figs. 3A and 5A; Supplemental Table 3). Similarly, Luisier et al. (2014) reported the same phenomenon for Cyp2b10 in PXR and CAR double KO mice. Unlike our data, the Ugt2b1 gene is downregulated only in female TCPOBOP-treated CAR-null mice and there is no change at the endogenous level or under PCN treatment in males or females (Aleksunes and Klaassen, 2012). Our observation on the regulation of Ugt $2 \mathrm{~b} 1$ at the endogenous level by both receptors in male rats may be species specific.

The major CYP3A metabolizing enzyme and PXR responsive gene in humans is CYP3A4; in mice it is Cyp3a1 1 and in rats it is Cyp3a23/3a1. The rat Cyp3a9 is conserved across the other CYP3A minor subfamily members in mice (82\% identity to Cyp3a13; 65\% to Cyp3a11; tblastn, data not shown) and humans (76\% to CYP3A7; 75\% to CYP3A5; 69\% to CYP3A43; 65\% to CYP3A4; tblastn, data not shown). Mouse Cyp3a13 is induced by PCN and TCPOBOP (Slatter et al., 2009), TCPOBOP (Cui and Klaassen, 2016), and the human CYP3A7 and CYP3A43 by rifampicin (PXR activator) not 6-(4-chlorophenyl) imidazo-[2,1-b][1,3] thiazole-5-carbaldehyde $O$-(3,4-dichloro-benzyl) oxime (CAR activator) (Kandel et al., 2016). In our study, we observed PCN activation of Cyp3a9 in WT and $\mathrm{PXR}^{-1-}$ but not in $\mathrm{CAR}^{-1-}$ and $\mathrm{PXR}^{-/-} / \mathrm{CAR}^{-/-}$. The endogenous levels of Cyp3a9 were significantly elevated in $\mathrm{CAR}^{-/-}$and $\mathrm{PXR}^{-/-} / \mathrm{CAR}^{-1-}$ and slightly reduced in $\mathrm{PXR}^{-1-}$ (not statistically significant), which suggests that CAR suppresses endogenous Cyp3a9 levels in the absence of exogenous ligand. Therefore, CAR regulates Cyp3a9 at the endogenous level and in this case, PCN induced expression, even in PXR KO rats. It is likely some other factors (other nuclear receptors per se) that bind PCN may also regulate Cyp3a9. The expression of the human CYP3A7 and CYP3A5 was elevated in CAR KO HepaRG cells when compared with WT, with no change to CYP3A43 levels (Li et al., 2016). This suggests that some of the minor CYP3A family members are more CAR dependent than PXR, which regulates the major CYP3A family member across several species.

In summary, as expected, no nuclear receptor-specific agonistmediated induction of phase I and II drug/xenobiotic metabolizing enzymes and transporter genes were observed in these $\mathrm{KO}$ rats. Our results also suggest that PXR and CAR are involved in regulation of the 
basal expression level of different (yet overlapping) sets of drug metabolizing genes. When both PXR and CAR regulate a given gene, their effects are often counteractive, indicative of crosstalk between the two nuclear receptors. The regulation and signaling crosstalk between PXR and CAR has been linked to several other genes via protein-protein interactions (for reviews, see Oladimeji et al., 2016; Pavek, 2016). This suggests we should look beyond PXR and CAR xenobiotic function and broaden our search for genes involved in other pathways that may be potentially disrupted by the loss of these protein-protein interactions.

Isogenic KO models provide the perfect tool to dissect functions of individual genes, and these models are also useful in determining drug efficacy with or without nuclear receptors and whether inhibiting nuclear receptors would increase efficacy. PXR and CAR are both also drug targets themselves (Cheng et al., 2012; Gao and Xie, 2012; Banerjee et al., 2014). A full understanding of all the pathways the nuclear receptors are involved in would be critical for therapeutic success. While our data only looked at a small portion of pathways PXR and CAR regulate (primarily phase I and II drug/xenobiotic metabolizing enzymes and transporter expression levels), many other targets may be regulated completely differently. Whole genome RNA profiling in different tissues of WT and KO animals would be highly informative on all pathways PXR and CAR are involved in and allow one to better predict metabolism of new drugs as well as potentially target PXR and CAR for therapeutics.

It can be concluded from this study that our data have shown a good correlation between the rat and human responses upon nuclear receptor disruption. These models complement the current mouse models. However, the rat has the advantage of size, and therefore it is a good candidate for ease of use and precision of measurements. Further studies will be needed to determine the advantage of these rat models over their mouse counterpart.

\section{Acknowledgments}

We thank Dr. Joe Warren and Yumei Wu for micro-injection; Lara Reid, Andre Chambers, Lauren Klaskala, and Diana Ji for genotyping; and Leanne Mushinski for colony management.

\section{Authorship Contributions}

Participated in research design: Forbes, Kouranova, Cui.

Conducted experiments: Forbes, Kouranova, Tinker, Janowski, Cortner, McCoy.

Performed data analysis: Forbes, Cui.

Wrote or contributed to the writing of the manuscript: Forbes, Cui.

\section{References}

Aitman T, Dhillon P, and Geurts AM (2016) A RATional choice for translational research? Dis Model Mech 9:1069-1072.

Aleksunes LM and Klaassen CD (2012) Coordinated regulation of hepatic phase I and II drugmetabolizing genes and transporters using AhR-, CAR-, PXR-, PPAR $\alpha$-, and Nrf2-null mice. Drug Metab Dispos 40:1366-1379.

Amacher DE (2016) The regulation of human hepatic drug transporter expression by activation of xenobiotic-sensing nuclear receptors. Expert Opin Drug Metab Toxicol 12:1463-1477 England.

Anakk S, Huang W, Staudinger JL, Tan K, Cole TJ, Moore DD, and Strobel HW (2007) Gender dictates the nuclear receptor-mediated regulation of CYP3A44. Drug Metab Dispos 35:36-42.

Banerjee M, Robbins D, and Chen T (2014) Targeting xenobiotic receptors PXR and CAR in human diseases. Drug Discov Today 20:618-628.

Brown AJ, Fisher DA, Kouranova E, McCoy A, Forbes K, Wu Y, Henry R, Ji D, Chambers A Warren J, et al. (2013) Whole-rat conditional gene knockout via genome editing. Nat Methods 10:638-640.

Cheng J, Shah YM, and Gonzalez FJ (2012) Pregnane X receptor as a target for treatment of inflammatory bowel disorders. Trends Pharmacol Sci 33:323-330.

Cheng X and Klaassen CD (2006) Regulation of mRNA expression of xenobiotic transporters by the pregnane $\mathrm{X}$ receptor in mouse liver, kidney, and intestine. Drug Metab Dispos 34: $1863-1867$.

Cui JY and Klaassen CD (2016) RNA-Seq reveals common and unique PXR- and CAR-target gene signatures in the mouse liver transcriptome. Biochim Biophys Acta 1859:1198-1217.

Cui X, Ji D, Fisher DA, Wu Y, Briner DM, and Weinstein EJ (2011) Targeted integration in rat and mouse embryos with zinc-finger nucleases. Nat Biotechnol 29:64-67.

Dickins M (2004) Induction of cytochromes P450. Curr Top Med Chem 4:1745-1766.
Dogra SC, Whitelaw ML, and May BK (1998) Transcriptional activation of cytochrome P450 genes by different classes of chemical inducers. Clin Exp Pharmacol Physiol 25:1-9.

Fang HL, Strom SC, Cai H, Falany CN, Kocarek TA, and Runge-Morris M (2005) Regulation of human hepatic hydroxysteroid sulfotransferase gene expression by the peroxisome proliferatoractivated receptor alpha transcription factor. Mol Pharmacol 67:1257-1267.

Gao J and Xie W (2012) Targeting xenobiotic receptors PXR and CAR for metabolic diseases. Trends Pharmacol Sci 33:552-558.

Giguère V (1999) Orphan nuclear receptors: from gene to function. Endocr Rev 20:689-725

Guo GL, Staudinger J, Ogura K, and Klaassen CD (2002) Induction of rat organic anion transporting polypeptide 2 by pregnenolone- $16 \alpha$-carbonitrile is via interaction with pregnane $\mathrm{X}$ receptor. Mol Pharmacol 61:832-839.

Guzelian J, Barwick JL, Hunter L, Phang TL, Quattrochi LC, and Guzelian PS (2007) Identification of genes controlled by the pregnane $\mathrm{X}$ receptor by microarray analysis of mRNAs from pregnenolone 16 $\alpha$-carbonitrile-treated rats. Toxicol Sci 94:379-387.

Hernandez JP, Mota LC, Huang W, Moore DD, and Baldwin WS (2010) Sexually dimorphic regulation and induction of $\mathrm{P} 450 \mathrm{~s}$ by the constitutive androstane receptor (CAR). Toxicology 256:53-64.

Hustert E, Zibat A, Presecan-Siedel E, Eiselt R, Mueller R, Fuss C, Brehm I, Brinkmann U, Eichelbaum M, Wojnowski L, et al. (2001) Natural protein variants of pregnane X receptor with altered transactivation activity toward CYP3A4. Drug Metab Dispos 29:1454-1459.

Kandel BA, Thomas M, Winter S, Damm G, Seehofer D, Burk O, Schwab M, and Zanger UM (2016) Genomewide comparison of the inducible transcriptomes of nuclear receptors CAR, PXR and PPAR $\alpha$ in primary human hepatocytes. Biochim Biophys Acta 1859:1218-1227.

Kelley M, Lambert I, Merrill J, and Safe S (1985) 1,4-Bis[2-(3,5-dichloropyridyloxy)]benzene (TCPOBOP) and related compounds as inducers of hepatic monooxygenases. Structure-activity effects. Biochem Pharmacol 34:3489-3494.

Kliewer SA, Moore JT, Wade L, Staudinger JL, Watson MA, Jones SA, McKee DD, Oliver BB, Willson TM, Zetterström RH, et al. (1998) An orphan nuclear receptor activated by pregnanes defines a novel steroid signaling pathway. Cell 92:73-82.

Li D, Mackowiak B, Brayman TG, Mitchell M, Zhang L, Huang SM, and Wang H (2016) Genome-wide analysis of human constitutive androstane receptor (CAR) transcriptome in wildtype and CAR-knockout HepaRG cells. Biochem Pharmacol 98:190-202.

Lichti-Kaiser K, Xu C, and Staudinger JL (2009) Cyclic AMP-dependent protein kinase signaling modulates pregnane $\mathrm{x}$ receptor activity in a species-specific manner. J Biol Chem 284:6639-6649.

Luisier R, Lempiäinen H, Scherbichler N, Braeuning A, Geissler M, Dubost V, Müller A, Scheer N, Chibout SD, Hara H, et al. (2014) Phenobarbital induces cell cycle transcriptional responses in mouse liver humanized for constitutive androstane and pregnane X receptors. Toxicol Sci 139:501-511.

Maglich JM, Stoltz CM, Goodwin B, Hawkins-Brown D, Moore JT, and Kliewer SA (2002) Nuclear pregnane $\mathrm{X}$ receptor and constitutive androstane receptor regulate overlapping but distinct sets of genes involved in xenobiotic detoxification. Mol Pharmacol 62:638-646.

Mangelsdorf DJ and Evans RM (1995) The RXR heterodimers and orphan receptors. Cell 83: 841-850.

Oladimeji P, Cui H, Zhang C, and Chen T (2016) Regulation of PXR and CAR by protein-protein interaction and signaling crosstalk. Expert Opin Drug Metab Toxicol 12:997-1010.

Pavek P (2016) Pregnane X receptor (PXR)-mediated gene repression and cross-talk of PXR with other nuclear receptors via coactivator interactions. Front Pharmacol 7:456.

Pavek P and Dvorak Z (2008) Xenobiotic-induced transcriptional regulation of xenobiotic metabolizing enzymes of the cytochrome P450 superfamily in human extrahepatic tissues. Curr Drug Metab 9:129-143.

Pelkonen O, Turpeinen M, Hakkola J, Honkakoski P, Hukkanen J, and Raunio H (2008) Inhibition and induction of human cytochrome P450 enzymes: current status. Arch Toxicol 82:667-715.

Scheer N, Ross J, Rode A, Zevnik B, Niehaves S, Faust N, and Wolf CR (2008) A novel panel of mouse models to evaluate the role of human pregnane $\mathrm{X}$ receptor and constitutive androstane receptor in drug response. J Clin Invest 118: 3228-3239.

Slatter JG, Cheng O, Cornwell PD, de Souza A, Rockett J, Rushmore T, Hartley D, Evers R, He Y, Dai X, et al. (2009) Microarray-based compendium of hepatic gene expression profiles for prototypical ADME gene-inducing compounds in rats and mice in vivo. Xenobiotica 36:902-937.

Staudinger JL, Goodwin B, Jones SA, Hawkins-Brown D, MacKenzie KI, LaTour A, Liu Y, Klaassen CD, Brown KK, Reinhard J, et al. (2001) The nuclear receptor PXR is a lithocholic acid sensor that protects against liver toxicity. Proc Natl Acad Sci USA 98:3369-3374.

Staudinger JL, Madan A, Carol KM, and Parkinson A (2003) Regulation of drug transporter gene expression by nuclear receptors. Drug Metab Dispos 31:523-527.

Timsit YE and Negishi M (2007) CAR and PXR: the xenobiotic-sensing receptors. Steroids 72 : 231-246

Tolson AH and Wang H (2010) Regulation of drug-metabolizing enzymes by xenobiotic receptors: PXR and CAR. Adv Drug Deliv Rev 62:1238-1249.

Uppal H, Toma D, Saini SPS, Ren S, Jones TJ, and Xie W (2005) Combined loss of orphan receptors PXR and CAR heightens sensitivity to toxic bile acids in mice. Hepatology 41:168-176.

Wallace BD, Betts L, Talmage G, Pollet RM, Holman NS, and Redinbo MR (2013) Structural and functional analysis of the human nuclear xenobiotic receptor PXR in complex with RXR $\alpha$. J Mol Biol 425:2561-2577.

Wang YM, Ong SS, Chai SC, and Chen T (2012) Role of CAR and PXR in xenobiotic sensing and metabolism. Expert Opin Drug Metab Toxicol 8:803-817.

Xia J and Kemper B (2007) Subcellular trafficking signals of constitutive androstane receptor: evidence for a nuclear export signal in the DNA-binding domain. Drug Metab Dispos 35:1489-1494.

Xie W, Barwick JL, Downes M, Blumberg B, Simon CM, Nelson MC, Neuschwander-Tetri BA, Brunt EM, Guzelian PS, and Evans RM (2000) Humanized xenobiotic response in mice expressing nuclear receptor SXR. Nature 406:435-439.

$\mathrm{Xu}$ C, Li CYT, and Kong ANT (2005) Induction of phase I, II and III drug metabolism/transport by xenobiotics. Arch Pharm Res 28:249-268.

Xu RX, Lambert MH, Wisely BB, Warren EN, Weinert EE, Waitt GM, Williams JD, Collins JL, Moore LB, Willson TM, et al. (2004) A structural basis for constitutive activity in the human CAR/RXR $\alpha$ heterodimer. Mol Cell 16:919-928.

Zhang J, Kuehl P, Green ED, Touchman JW, Watkins PB, Daly A, Hall SD, Maurel P, Relling M, Brimer C, et al. (2001) The human pregnane $\mathrm{X}$ receptor: genomic structure and identification and functional characterization of natural allelic variants. Pharmacogenetics 11:555-572.

Address correspondence to: Kevin P. Forbes, 2033 Westport Center Dr., Saint Louis, MO 63146. E-mail: k.forbes@horizondiscovery.com 